\title{
RNA sequencing of murine mammary epithelial stem-like cells (HC11) undergoing lactogenic differentiation and its comparison with embryonic stem cells
}

\author{
Trinadha Rao Sornapudi', Rakhee Nayak', Prashanth Kumar Guthikonda', Srinivas Kethavath', Sailu Yellaboina ${ }^{2}$ \\ and Sreenivasulu Kurukuti ${ }^{*}$ (B)
}

\begin{abstract}
Objectives: Understanding of transcriptional networks specifying HC11 murine mammary epithelial stem cell-like cells (MEC) in comparison with embryonic stem cells (ESCs) and their rewiring, under the influence of glucocorticoids (GC) and prolactin (PRL) hormones, is critical for elucidating the mechanism of lactogenesis. In this data note, we provide RNA sequencing data from murine MECs and ESCs, MECs treated with steroid hormone alone and in combination with PRL. This data could help in understanding temporal dynamics of mRNA transcription that impact the process of lactogenesis associated with mammary gland development. Further integration of these data sets with existing datasets of cells derived from various stages of mammary gland development and different types of breast tumors, should pave the way for effective prognosis and to develop therapies for breast cancer.
\end{abstract}

Data description: We have generated RNA-sequencing data representing steady-state levels of mRNAs from murine ESCs, normal MECs (N), MECs primed (P) with hydrocortisone (HC) alone and in combination with PRL hormone by using Illumina sequencing platform. We have generated $\sim 58$ million reads for ESCs with an average length of $\sim 100$ nt and an average 115 million good quality mapped reads with an average length of $150 \mathrm{nt}$ for different stages of MECs differentiation.

Keywords: Mammary epithelial cells, HC11 cells, Embryonic stem cells, Transcriptome, RNA sequencing, Cellular differentiation, Glucocorticoid signaling, Prolactin signaling, Lactogenesis

\section{Objective}

HC11 cells are PRL responsive epithelial cell clone, derived from the COMMA1D cells and originated from the mammary gland tissue of a pregnant BALB/c mouse and are widely used model system to study the lactogenic differentiation in vitro [1]. Undifferentiated state of MECs is maintained in the presence of Insulin and epidermal growth factor (EGF). They are stimulated to differentiate by withdrawal of EGF and supplemented initially

\footnotetext{
*Correspondence: skurukuti@uohyd.ac.in

1 Department of Animal Biology, School of Life Sciences, University

of Hyderabad, Gachibowli, Hyderabad 500046, India

Full list of author information is available at the end of the article
}

with insulin, GC and later in combination with PRL [2]. Glucocorticoids binds to cytosolic glucocorticoid receptor (GR) and functions via genomic and non-genomic pathways to accompany differential gene expression [3]. Further, PRL, a peptide hormone, upon binding to PRL receptor (PRLr) on plasma membrane initiates cascade of events which ultimately leads to the cytosolic dimerization and nuclear internalization of Stat $5 \mathrm{a} / \mathrm{b}$, to promote differential expression of genes [4]. Dissecting the gene regulatory networks that act in cohort and orchestrate mammary epithelial cells differentiation under the influence of lactogenic hormones is critical for elucidating the mechanism of lactogenesis in the context of mammary gland development and differentiation. Previous studies 
Table 1 Overview of data files/data sets

\begin{tabular}{llll}
\hline Label & Name of data file/data set & File types (file extension) & $\begin{array}{c}\text { Data repository and identifier } \\
\text { (DOI or accession number) }\end{array}$ \\
\hline Data file 1 & Embryonic Stem Cells Rep 1 & GSM2866581 \\
Data file 2 & Embryonic Stem Cells Rep 2 & .gz format & GSM2866582 \\
Data file 3 & Normal HC11 Rep 1 (N) & .gz format & GSM2866583 \\
Data file 4 & Normal HC11 Rep 2 (N) & .gz format & GSM2866584 \\
Data file 5 & Primed HC11 Rep 1 (P) & .gz format & GSM2866585 \\
Data file 6 & Primed HC11 Rep 2 (P) & .gz format & GSM2866586 \\
Data file 7 & Prolactin HC11 Rep 1 (PRL) & .gz format & GSM2866587 \\
Data file 8 & Prolactin HC11 Rep 2 (PRL) & .gz format & GSM2866588 \\
\hline
\end{tabular}

have made an attempt to profile transcriptome of MECs during lactogenic differentiation by using microarrays [5-7], which has its inherent limitations. In this current study, we comprehensively profiled transcriptome of two independent biological replicates each for ESCs, normal, primed and PRL treated MECs by high throughput RNA sequencing method using Illumina sequencing platform. We have used these RNA-Seq datasets to derive differentially expressed genes, pathways which play key roles in orchestrating lactogenic differentiation of MECs and presented our inferences in a manuscript that is currently under review [8]. These data sets are also useful in understanding temporal dynamics of transcriptome and gene expression associated with alternative splicing specific to lactogenesis.

\section{Data description}

We cultured R1 murine ESCs with standard recommended protocol [9] in presence of 2i medium. Normal MECs (N) were cultured in presence of insulin $(5 \mu \mathrm{g} / \mathrm{ml}$, Sigma \# 16634) and EGF (20 ng/ml, Sigma \# E4127), followed by priming (P) with HC ( $1 \mu \mathrm{g} / \mathrm{ml}$, Sigma \# H4001) and insulin $(5 \mu \mathrm{g} / \mathrm{ml}$, Sigma \# 16634) for $48 \mathrm{~h}$ and in combination with PRL $(5 \mu \mathrm{g} / \mathrm{ml}$, NIH \# NIDDK-oPRL-21) for $72 \mathrm{~h}$. Total RNA was extracted from two independent replicates each for ESCs, normal, primed and PRL treated MECs by using TRIzol ${ }^{\mathrm{TM}}$ (Invitrogen \# 15596026) according to manufacturer instruction. Total RNA was further purified by using $G$ Sure cell culture RNA isola-

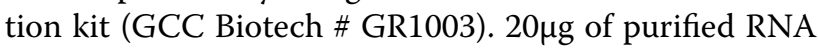
from each sample was treated with 10 Units of DNAse1 (Roche \# 04716728001) and were further purified by using G Sure cell culture RNA isolation kit. From each RNA sample, Ribosomal RNA was depleted by using Ribo-Zero kit (NEB\#E6310L) and further mRNAs were enriched by Oligo (dT) beads. Illumina paired end library was prepared as per the NEBNext ${ }^{\circledR}$ Ultra $^{\mathrm{TM}}$ RNA Library Prep Kit (NEB \# E7530S). All the libraries were paired end sequenced using illumina HiSeq 2500 sequencing platform. Raw sequence reads in FASTQ format were further processed to remove Illumina adaptor sequences by using Trimmomatic [10]. The resultant raw reads were compressed to .gz format and were deposited in GEO repository [11].

\section{Limitations}

The Illumina Hi-Seq 2500 platform used in this current study, generates shorter (100-150 nt) high quality reads and annotation of full length transcript information requires overlapping sequence reads and thus requires much deep sequencing of samples. In the current datasets, we generated $\sim 58,108,112,127$ million mappable reads for ESCs, normal $(\mathrm{N})$, primed $(\mathrm{P})$ and prolactin (PRL) treated MECs respectively. Though this level of sequencing depth is sufficient to derive expression and differential expression of mRNA transcripts and its alternative spliced forms, it might not be sufficient enough in finding variations to distinguish mutations, allelic or imprinting expression of genes [12]. Further, interrogation of low abundant mRNAs and long noncoding RNAs require much deeper sequencing of the samples ( $>200$ million). Though, one can assess few abundant microRNAs from these datasets, comprehensive characterization of miRNAs requires RNA sequencing of miRNA enriched population.

\section{Abbreviations}

EGF: epidermal growth factor; ESC: embryonic stem cells; HC: hydrocortisone; GC: glucocorticoids; GR: glucocorticoid receptor; MECs: mammary epithelial cells; PRL: prolactin; PRLr: prolactin receptor.

\section{Authors' contributions}

TRS and RN performed experiments. TRS, RN, PKG, SK1, SY and SK2 analyzed the data. TRS and SK2 wrote the manuscript. All authors read and approved the final manuscript.

\section{Author details}

${ }^{1}$ Department of Animal Biology, School of Life Sciences, University of Hyderabad, Gachibowli, Hyderabad 500046, India. ${ }^{2}$ CR Rao Advanced 
Institute of Mathematics, Statistics and Computer Sciences, University of Hyderabad Campus, Hyderabad 500046, India.

\section{Acknowledgements}

We thank Dr. Nancy E. Hynes for providing HC11 mammary epithelial cells. We also acknowledge the Computer Networking Facility of University of Hyderabad and DST FIST Level II Computing facility at the Department of Animal Biology, School of Life Sciences, University of Hyderabad, India for facilitating data analysis. Nucleome Informatics Pvt Ltd. Hyderabad, India and Clevergene Biocorp Pvt Ltd. Bangalore, India for sequencing of RNA libraries from MECs and ESCs respectively. Research fellowship from UGC-CSIR to TS and PKG, RGNF fellowship to RN and ICMR senior research fellowship to SK1 are duly acknowledged.

\section{Competing interests}

The authors declare that they have no competing interests.

\section{Availability of data materials}

The data described in this Data note can be freely and openly accessed in the GEO repository via GEO-Accession No. GSE107419 https://identifiers.org/ncbi/ GEO:GSE107419. Please see Table 1 and reference list for details and links to the data.

\section{Consent for publication \\ Not applicable.}

\section{Ethics approval and consent to participate}

Not applicable.

\section{Funding}

This project was funded by National Institute of Animal Biotechnology, Department of Biotechnology, India (NIAB/CP/107/2012) and Indian Council of Medical Research, India (90/09/2012/SCRT(TF)/BMS) to SK2.

\section{Publisher's Note}

Springer Nature remains neutral with regard to jurisdictional claims in published maps and institutional affiliations.

Received: 9 February 2018 Accepted: 6 April 2018

Published online: 11 April 2018

\section{References}

1. Danielson KG, Oborn CJ, Durban EM, Butel JS, Medina D. Epithelial mouse mammary cell line exhibiting normal morphogenesis in vivo and functional differentiation in vitro. Proc Natl Acad Sci USA. 1984;81(12):3756-60

2. Hynes NE, Taverna D, Harwerth IM, Ciardiello F, Salomon DS, Yamamoto T, Groner B. Epidermal growth factor receptor, but not c-erbB-2, activation prevents lactogenic hormone induction of the beta-casein gene in mouse mammary epithelial cells. Mol Cell Biol. 1990;10(8):4027-34.

3. Oakley RH, Cidlowski JA. The biology of the glucocorticoid receptor: new signaling mechanisms in health and disease. J Allergy Clin Immunol. 2013;132(5):1033-44.

4. Radhakrishnan A, Raju R, Tuladhar N, Subbannayya T, Thomas JK, Goel R, Telikicherla D, Palapetta SM, Rahiman BA, Venkatesh DD, et al. A pathway map of prolactin signaling. J Cell Commun Signal. 2012;6(3):169-73.

5. Perotti C, Wiedl T, Florin L, Reuter H, Moffat S, Silbermann M, Hahn M, Angel P, Shemanko CS. Characterization of mammary epithelial cell line $\mathrm{HC} 11$ using the NIA $15 \mathrm{k}$ gene array reveals potential regulators of the undifferentiated and differentiated phenotypes. Differentiation 2009;78(5):269-82.

6. Wang W, Jose C, Kenney N, Morrison B, Cutler ML. Global expression profiling reveals regulation of $C T$ GF/CCN2 during lactogenic differentiation. J Cell Commun Signal. 2009:3(1):43-55.

7. Williams C, Helguero L, Edvardsson K, Haldosen LA, Gustafsson JA. Gene expression in murine mammary epithelial stem cell-like cells shows similarities to human breast cancer gene expression. Breast Cancer Res. 2009;11(3):R26.

8. Sornapudi TR, Nayak R, Guthikonda PK, Pasupuleti AK, Kethavath S, Uppada V, Mondal S, Yallaboina S, Kurukuti S. Comprehensive profiling of trancripitonal networks specific for lactogenic differentiation of mammary epithelial stem-like cells (communicated).

9. Bibel M, Richter J, Lacroix E, Barde YA. Generation of a defined and uniform population of CNS progenitors and neurons from mouse embryonic stem cells. Nat Protoc. 2007;2(5):1034-43.

10. Bolger AM, Lohse M, Usadel B. Trimmomatic: a flexible trimmer for Illumina sequence data. Bioinformatics. 2014;30(15):2114-20.

11. Sornapudi T, Nayak R, Uppada V, Guthikonda PK, Kethavath S, Yellaboina S, Pasupulati AK, Kurukuti S. Comprehensive mapping of transcriptional networks specifying lactogenic differentiation of murine mammary epithelial stem like cells. Gene Expr Omnibus GSE107419. 2018. https:// identifiers.org/ncbi/GEO:GSE107419.

12. Liu Y, Ferguson JF, Xue C, Silverman IM, Gregory B, Reilly MP, Li M. Evaluating the impact of sequencing depth on transcriptome profiling in human adipose. PLoS ONE. 2013;8(6):e66883.
Ready to submit your research? Choose BMC and benefit from:

- fast, convenient online submission

- thorough peer review by experienced researchers in your field

- rapid publication on acceptance

- support for research data, including large and complex data types

- gold Open Access which fosters wider collaboration and increased citations

- maximum visibility for your research: over 100M website views per year

At BMC, research is always in progress.

Learn more biomedcentral.com/submissions 